\title{
Decision-making process in the pre-dialysis CKD patients: do anxiety, stress and depression matter?
}

\author{
Cicero Italo L. Bezerra', Bruno C. Silva ${ }^{1}$ and Rosilene M. Elias ${ }^{1,2^{*}}$
}

\begin{abstract}
Background: The transition from pre-dialysis chronic kidney disease (CKD) to renal replacement therapy (RRT) is a stressful event. Anxiety, depression and stress are frequent conditions in this population, and might play a role on the choice of dialysis modality.

Methods: This is a prospective study that included stages 4-5 CKD patients during a dialysis multi-disciplinary education program. Demographic, clinical, and laboratory data were evaluated. Hospital Anxiety and Depression Scale and a Perceived Stress Scale assessed levels of anxiety, depression and stress, respectively.

Results: A total of 67 from 190 recruited patients were included (59 15 years, 54\% males). Comparing patients who chose peritoneal dialysis (PD) and hemodialysis (HD), there were no differences on anxiety $(p=0.55)$, and depression scores $(p=0.467)$, and stress $(p=0.854)$. Anxious $(p=0.007)$ and depressive $(p=0.030)$ patients presented lower levels of phosphate than those not affected. There was a significant correlation $(p<0.0001)$ between anxiety and depression scores $\left(R^{2}=0.573\right)$, anxiety and stress scores $\left(R^{2}=0.542\right)$, depression and stress scores $\left(R^{2}=0.514\right)$. At the end of study, $29.8 \%$ of patients had already started on dialysis, and scores of anxiety, depression and stress reduced significantly (all $p$ values $<0.0001$ ), from $5.9 \pm 3.3$ to $1.8 \pm 1.8$, from $7.7 \pm 4.0$ to $3.8 \pm 2.9$ and from $28.6 \pm 7.8$ to $10.0 \pm 6.2$, respectively, regardless of which therapy was chosen.
\end{abstract}

Conclusion: Depression, anxiety and perceived stress during final stages of CKD do not seem to be related to the choice of dialysis therapy and tend to decrease after dialysis initiation.

Keywords: Anxiety, Stress, Depression, Peritoneal dialysis, Hemodialysis

\section{Background}

Depression and anxiety are frequent comorbid disorders among chronic kidney disease (CKD) patients, with estimated prevalence of approximately $25 \%$ in this population, [1] and are associated with worse outcomes, such as progression to end-stage renal disease (ESRD) and mortality [2-5]. The transition from predialysis management to renal replacement therapy (RRT) is a stressful event in the course of CKD, leading to challenges and decisions that might increase their susceptibility to anxiety, mood disorders or even exacerbate psychological issues that already exist [6].

\footnotetext{
*Correspondence: rosilenemotta@hotmail.com

${ }^{1}$ Nephrology, Hospital das Clinicas HCFMUSP, Universidade de Sao Paulo, São Paulo, Brazil

${ }^{2}$ Universidade Nove de Julho (UNINOVE), São Paulo, Brazil
}

Choosing an RRT might be a dilemma for both patients and nephrologists since different options of RRT are available for CKD patients. Preemptive kidney transplantation, which might lead to higher life expectancy and quality of life [7], is an option for these patients if a living donor is available. Therefore, peritoneal dialysis (PD) and hemodialysis (HD) are the most common modalities offered to patients requiring RRT.

The RRT decision-making process is challenging; nephrologists should provide education and support to help choose the dialysis modality that best reflects the patient's personal values and lifestyle $[8,9]$. Nevertheless, frequently only clinical, social and economic variables are taken into account for such decision, while mental health is often neglected.

(c) The Author(s). 2018 Open Access This article is distributed under the terms of the Creative Commons Attribution 4.0 International License (http://creativecommons.org/licenses/by/4.0/), which permits unrestricted use, distribution, and reproduction in any medium, provided you give appropriate credit to the original author(s) and the source, provide a link to the Creative Commons license, and indicate if changes were made. The Creative Commons Public Domain Dedication waiver (http://creativecommons.org/publicdomain/zero/1.0/) applies to the data made available in this article, unless otherwise stated. 
Despite the clear association between mood disorders and CKD, there is limited data regarding the influence of such disorders on the decision-making process in predialysis CKD patients. Given the complexity of the process of choosing a dialysis modality, the goal of this study is to determine the extent of which the severity of anxiety, depression, and stress among pre-dialytic patients can interfere with the choice of the RRT method.

\section{Methods}

This was a prospective study that recruited patients from a tertiary academic hospital in Sao Paulo, Brazil, during a dialysis education program (DEP), given by a multidisciplinary team of nephrologist, nurse, psychologist, dietician and social worker. The eligibility criteria were adult pre-dialysis CKD (stages 4 and 5) patients who attended the DEP and agreed to participate in the study by signing the Informed Consent Form. Demographic, clinical, and laboratory data were obtained from medical records. At study entry, patients answered the Portuguese version of the self-administered Hospital Anxiety and Depression Scale (HADS) and Perceived Stress Scale (PSS) to assess their scores of anxiety, depression, and stress, respectively, as described below. Participants also filled in a survey with questions about the reasons why they decided for a particular dialysis modality.

\section{Hospital anxiety and depression scale (HADS)}

This tool has 14 items that evaluate anxiety and depression severity, yet excluding somatic symptoms to prevent bias from physical disorders. Scores $\geq 9$ establish the diagnosis of anxiety and depression [10].

\section{Perceived stress scale (PSS)}

This scale is composed of 14 items that assess how individuals perceive stressful situations. The total sum of the scores can reach 56 points. Higher scores reflect greater amounts of perceived stress [11].

\section{Statistical analysis}

Continuous data were presented as mean and SD or median $(25,75)$ according to data distribution, as appropriate. Categorical data were displayed as $\mathrm{N}$ and percentage. Comparison between the groups of patients who chose PD or HD was performed using the independent $\mathrm{t}$-test or the alternative Mann-Whitney U-test, as appropriate. A $p$-value $<0.05$ was considered statistically significant.

\section{Results}

A total of 190 adult patients who had been diagnosed with Stage 4 or 5 CKD and were assigned to DEP were randomly selected and asked to participate in the research. Out of the 190 candidates, a total of 69 patients agreed to participate in the study. Two participants were excluded from the study due to a lack of final decision on RRT modality. Therefore, a total sample of 67 patients was included. From this population, 22 chose PD and 45 preferred HD as future RRT option.

Patient's demographic and social characteristics are shown in Table 1. PD and HD groups did not differ regarding any demographic, clinical and biochemical characteristic. Mean age of the patients was $59 \pm 15$ years, similar between PD and HD groups. The sample is comprised of $54 \%$ males, $59 \%$ white, $56 \%$ married patients. Almost $78 \%$ of the sample had an education level ending before or at ninth grade, particularly in the group of patients who chose Peritoneal Dialysis - PD (82\%) when compared to the group who elected Hemodialysis - HD (71\%). The leading causes of CKD were Nephrosclerosis and Diabetic Nephropathy.

Patients were asked about particular reasons that made them chose PD or HD. Family and work issues accounted $32.8 \%$ and $7.5 \%$, respectively. Patients who chose PD over HD were more likely to select work issue (9.1\% vs. $6.7 \%)$.

Table 2 shows median scores of anxiety, depression and stress scores in the entire group as well as according to the dialysis modality chosen. The median of Anxiety scores was 6, ranging from 1 to 17, which was not different when comparing PD and HD groups (Fig. 1a). Patients classified as anxious corresponded to $45 \%$ of the PD group and $29 \%$ of the HD group $(p=0.180)$. There was no difference between anxious and non-anxious patients regarding gender $(p=0.483)$, race $(p=0.277)$, education level $(p=0.305)$, and marital status $(p=0.617)$. Anxious patients presented lower levels of phosphate than non-anxious subjects $(4.3 \pm 0.8$ vs. $5.4 \pm 2.5, p=0.007)$.

Median depression scores were 9, ranging from 2 to 19. Median depression scores in PD and HD groups were not significantly different (Table 2 and Fig. 1b). Using a cut-off value of $\geq 9$, we found a similar prevalence of depression in HD and PD groups of $58 \%$ and $41 \%$, respectively $(p=0.194)$. Depressive patients presented lower levels of phosphate $(4.5 \pm 1.2$ vs. $5.6 \pm 2.7$, $p=0.030)$, and a tendency to higher PTH levels [180 $(127,305)$ vs. $153(98,248) \mathrm{pg} / \mathrm{ml}, p=0.102]$.

Levels of stress did not differ significantly between groups of patients who elected PD and HD, as shown in Table 2 while median values for the entire population were $30(21,35)$. As seen in Fig. 1c, scores of stress varied from 18 to 47 in PD group, and from 17 to 42 in HD group.

When analyzing the entire population, anxiety and depression scores show a positive and strong correlation $\left(R^{2}=0.573 ; p<0.0001 ;\right.$ Fig. $\left.2 \mathrm{a}\right)$. There was a 
Table 1 Baseline patient characteristics

\begin{tabular}{|c|c|c|c|c|}
\hline \multirow[b]{3}{*}{ Characteristic } & \multirow{3}{*}{$\begin{array}{l}\text { Total } \\
(N=67)\end{array}$} & \multicolumn{3}{|c|}{ Dialysis modality } \\
\hline & & \multirow{2}{*}{$\begin{array}{l}\mathrm{PD} \\
(N=22)\end{array}$} & \multirow{2}{*}{$\begin{array}{l}\mathrm{HD} \\
(N=45)\end{array}$} & \multirow[t]{2}{*}{$p$} \\
\hline & & & & \\
\hline Age, years & $59 \pm 15$ & $59 \pm 17$ & $58 \pm 14$ & NS \\
\hline Male, \% & 53.7 & 54.5 & 53.3 & NS \\
\hline White, \% & 63.8 & 71.4 & 59.5 & NS \\
\hline \multicolumn{5}{|l|}{ Primary renal disease, $\%$} \\
\hline Nephrosclerosis & 30.8 & 22.7 & 34.9 & \multirow[t]{4}{*}{ NS } \\
\hline Diabetic Nephropathy & 24.6 & 22.7 & 25.6 & \\
\hline Glomerulonephritis & 12.3 & 9.1 & 14.0 & \\
\hline Others and unknown & 32.3 & 45.5 & 25.5 & \\
\hline \multicolumn{5}{|l|}{ Comorbidities, \% } \\
\hline Diabetes & 41.5 & 40.9 & 41.9 & NS \\
\hline Hypertension & 81.5 & 77.3 & 83.7 & NS \\
\hline Myocardial infarction & 10.6 & 4.5 & 13.6 & NS \\
\hline Stroke & 4.5 & 0 & 6.8 & NS \\
\hline Congestive heart failure & 15.2 & 9.1 & 18.2 & NS \\
\hline Atrial Fibrillation & 7.6 & 9.1 & 6.8 & NS \\
\hline Peripheral arterial disease & 12.1 & 9.1 & 13.6 & NS \\
\hline COPD & 6.1 & 0 & 9.1 & NS \\
\hline Married, \% & 60.9 & 63.6 & 59.5 & NS \\
\hline \multicolumn{5}{|l|}{ Higher education level, \% } \\
\hline Before ninth grade & 77.8 & 81.8 & 75.6 & \multirow[t]{3}{*}{ NS } \\
\hline Up to high school & 15.9 & 18.2 & 14.6 & \\
\hline College/University & 6.3 & 0 & 9.8 & \\
\hline \multicolumn{5}{|l|}{ Laboratory values } \\
\hline eGFR, $\left(\mathrm{ml} / \mathrm{kg} / 1.73 \mathrm{~m}^{2}\right)$ & $16 \pm 7$ & $14 \pm 6$ & $17 \pm 7$ & NS \\
\hline Creatinine (mg/dL) & $4.1 \pm 1.7$ & $4.4 \pm 1.6$ & $4.0 \pm 1.8$ & NS \\
\hline Urea (mg/dL) & $124 \pm 50$ & $127 \pm 47$ & $123 \pm 52$ & NS \\
\hline Potassium (mmol/L) & $4.7 \pm 0.7$ & $4.7 \pm 0.7$ & $4.7 \pm 0.7$ & NS \\
\hline Albumin (g/dL) & $4.0 \pm 0.6$ & $4.1 \pm 0.6$ & $4.0 \pm 0.6$ & NS \\
\hline Phosphorus (mg/dL) & $5.0 \pm 2.1$ & $5.3 \pm 2.4$ & $4.9 \pm 2.0$ & NS \\
\hline PTH (pg/mL) & $177(107,292)$ & $215(112,265)$ & $153(98,298)$ & NS \\
\hline Total Calcium (mg/dL) & $9.2 \pm 0.8$ & $9.0 \pm 1.0$ & $9.3 \pm 0.7$ & NS \\
\hline 25-hydroxyvitamin D (ng/mL) & $23.5 \pm 11.3$ & $20.8 \pm 14$ & $25.2 \pm 9.2$ & NS \\
\hline Bicarbonate $(\mathrm{mmol} / \mathrm{L})$ & $21.4 \pm 6.3$ & $20.3 \pm 8.5$ & $22.1 \pm 4.6$ & NS \\
\hline Alkaline phosphatase (UI/L) & $103 \pm 61$ & $114 \pm 44$ & $98 \pm 69$ & NS \\
\hline Iron ( $\mu \mathrm{g} / \mathrm{ml})$ & $68.6 \pm 28.8$ & $75 \pm 41$ & $65 \pm 20$ & NS \\
\hline Ferritin (ng/ml) & $176(79,394)$ & $121(65,368)$ & $209(92,408)$ & NS \\
\hline Hemoglobin $(\mathrm{g} / \mathrm{L})$ & $11.0 \pm 2.8$ & $10.9 \pm 3.1$ & $11.1 \pm 2.6$ & NS \\
\hline
\end{tabular}

eGFR estimated glomerular filtration rate, COPD chronic obstructive pulmonary disease, NS not significant

correlation between scores of anxiety and stress $\left(R^{2}=\right.$ 0.542; $p<0.0001$; Fig. 2b) and also between depression and stress scores $\left(\mathrm{R}^{2}=0.514 ; p<0.0001\right.$; Fig. $\left.2 \mathrm{c}\right)$.
At the end of the study, 20 patients (30\%) had already started on dialysis. From this sample, eight patients chose PD as preferred therapy, but only five actually 
Table 2 Levels of Anxiety, depression and stress according to chosen dialysis modality

\begin{tabular}{lllll}
\hline & Total & \multicolumn{3}{l}{ Dialysis modality } \\
\cline { 3 - 5 } & & PD & HD & $p$ \\
Scores & $(N=67)$ & $(N=22)$ & $(N=45)$ & \\
\hline Anxiety & $6(4,10)$ & $7(4,10)$ & $5(4,10)$ & NS \\
Depression & $9(5,12)$ & $7.5(4,12)$ & $9(6,12)$ & NS \\
Stress & $30(21,35)$ & $30(20,34)$ & $29(22,36)$ & NS \\
\hline
\end{tabular}

Values are expressed as median $(25,75)$

NS not significant

started PD and the three remaining started HD. All patients who had chosen HD actually started it. We have applied all scales within the first 3 months after dialysis initiation. A subanalysis of this sample revealed that scores of anxiety, depression, and stress reduced significantly regardless of which therapy was chosen (Table 3).

\section{Discussion}

This study aimed to understand if symptoms of depression, anxiety or stress in patients with CKD have any impact on the choice of dialysis therapy. We found that the prevalence of both anxiety and depression is high in this subset of patients, regardless of chosen therapy, and that perceived stress is associated with both conditions. Nevertheless, after starting dialysis, there was a significant reduction in overall depression, anxiety, and stress scores.

In CKD patients, depression has been implicated not only with poor outcomes and low adherence to general medical treatment [12] but also with anxiety and low quality of life [13]. However, the major concern of healthcare providers is the association of depression with higher risk of initiation of dialysis, hospitalization, and death in this population [2-5]. This is of huge clinical relevance since the prevalence of depression across different populations ranges from 7 to $47 \%$ [13-16]. In the current study, we found a point prevalence of depression of $58 \%$ and $41 \%$ in CKD patients who chose $\mathrm{HD}$ and PD as dialysis methods, respectively. Such finding represents a novelty since the impact of depression on the choice of dialysis method is still unclear. Additionally, depression was associated with both anxiety and perceived stress.

Anxiety symptoms often co-occur with depression not only in the general population but also in patients undergoing dialysis [1]. Few studies have addressed anxiety in CKD patients and its prevalence across cohorts varies from 27 to $31 \%$ [3, 13], which is similar to what we found. So far, anxiety seems to play a role in strengthening the negative association between depression and quality of life in dialysis patients, thus reducing the ability to cope with this condition [1].

We found higher levels of perceived stress in comparison to a US cohort, which described a mean PSS score of 5.6 in 65 patients with CKD 4 and 5 [17]. Recently, higher PSS scores were associated with increased mortality in patients with multiple comorbidities [18]. Since stress could be a modifiable risk factor, possibly associated with lifestyle choices, diagnosis and management of this condition could improve management of CKD care.

Regardless of whether or not the patient has depressive or anxious symptoms during the course of CKD, it does not seem to influence the choice of dialysis. Supposedly, it would be convenient for a depressive/anxious patient not to choose $\mathrm{PD}$, since such method requires self-care. The opposed finding in this study carries out an important message to health care providers since the presence of these symptoms does not necessarily indicate an alternative with less need for self-care.

We also found a correlation between depression and anxiety with lower phosphate levels. This is not entirely new since it has been previously demonstrated $[19,20]$, although in non-CKD population. In the general population, this correlation can be explained by
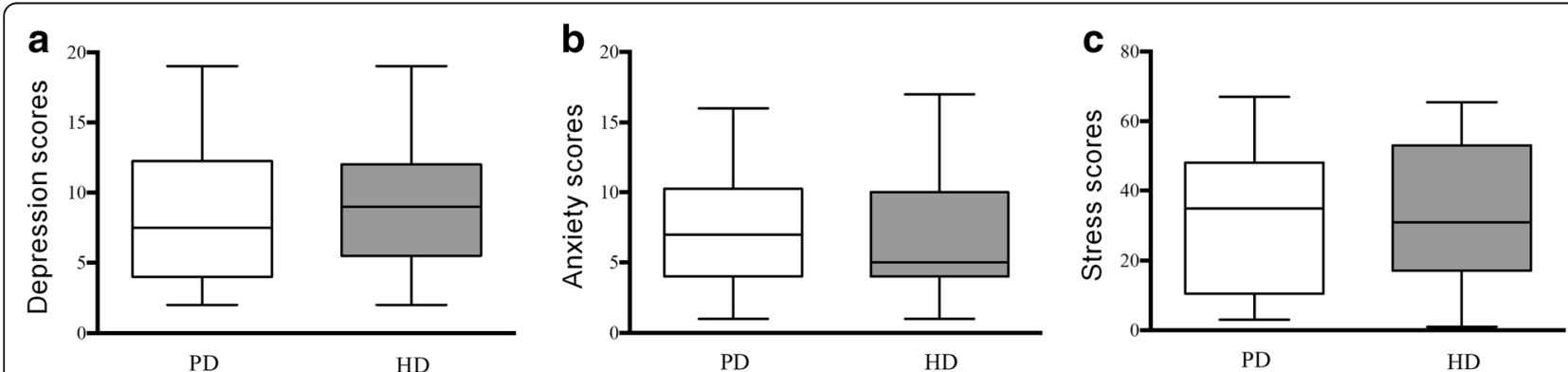

Fig. 1 Depression (a), Anxiety (b), and Perceived stress (c) levels comparison between peritoneal dialysis (PD) and hemodialysis (HD) groups. White bars represent PD group and grey bars represent HD group. Box and whiskers represent median and range 

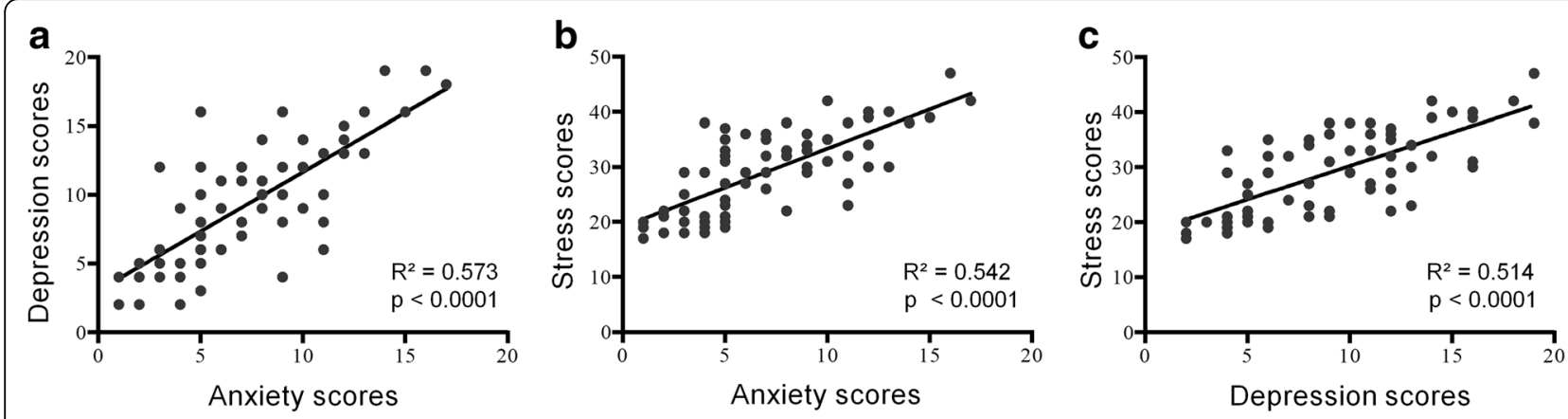

Fig. 2 Correlations between anxiety and depression scores (a), anxiety and stress scores (b), and depression and stress scores (c)

alkalosis caused by hyperventilation, which is commonly found in patients with anxiety and depression [21]. However, regarding pre-dialysis CKD patients, low levels of phosphate might reflect malnutrition. Serum calcium and hormones involved in calcium homeostasis are less likely to be involved in this process [19]. Accordingly, we did not find any associations between depression or anxiety and $\mathrm{PTH}$, vitamin D or calcium levels.

Another interesting finding was the predilection for HD rather than PD. Patients had no limitations in choosing between both therapies. We believe that this particular preference for HD in Brazil is due to cultural issues, as self-care is the main barrier to choosing PD. Many patients prefer a professional person to take care of dialysis therapy, even though it might lead to less freedom to work or travel.

This study has some limitations, as comprised a small sample size and individuals were included from a single center. Additionally, results can be biased since patients who agreed to participate could be more motivated than those who refused to participate. Additionally, cut-off values for diagnosis of anxiety/depression in the CKD population are still under debate. The current study has also some strength: to the best of our knowledge, this is the first study that assessed the impact of depression, anxiety, and stress in an RRT decisionmaking process. Furthermore, we have demonstrated that these symptoms improve after dialysis initiation. The relationship between hypophosphatemia and

Table 3 Levels of Anxiety, depression and stress before in after dialysis initiation

\begin{tabular}{llll}
\hline & $\begin{array}{l}\text { Before dialysis initiation } \\
(N=20)\end{array}$ & $\begin{array}{l}\text { After dialysis initiation } \\
(N=20)\end{array}$ & $p$ \\
\hline Anxiety & $5.9 \pm 3.4$ & $1.8 \pm 1.8$ & 0.0001 \\
Depression & $7.6 \pm 4.0$ & $3.8 \pm 2.9$ & 0.0001 \\
Stress & $28.6 \pm 7.8$ & $10.0 \pm 6.2$ & 0.0001 \\
\hline
\end{tabular}

Values are mean \pm SD depressive/anxious symptoms in the setting of CKD deserves further investigation.

\section{Conclusions}

In summary, depression, anxiety and perceived stress during final stages of CKD do not seem to influence the choice of dialysis therapy. Additionally, after starting dialysis, it is observed a significant reduction in overall depression, anxiety, and stress scores.

\section{Abbreviations \\ CKD: Chronic kidney disease; DEP: Dialysis education program; HADS: Hospital anxiety and depression scale; HD: Hemodialysis; PD: Peritoneal dialysis; PSS: Perceived stress scale; RRT: Renal replacement therapy}

\section{Acknowledgments}

The authors thankfully acknowledge the participation of predialysis patients in this study. We thank Regina (Social Worker), Glauce (Psychologist), and Keisy (Nurse), for assistance with recruitment and the crew from Dialysis Education Program.

\section{Availability of data and materials}

Data available from corresponding author (Rosilene Motta Elias).

\section{Authors' contributions}

CILB contributed to study conception, design, data analysis, and contributed to the development of the manuscript. BCS contributed to study conception, design and development of the manuscript. RME contributed to study conception, design, data analysis, and contributed to the development of the manuscript. All authors have read and approved the final version of this manuscript.

\section{Ethics approval and consent to participate}

The study was performed according to the guidelines of the Helsinki Declaration and was approved by the Research Ethics Boards of University of São Paulo (CAPpesq \#30396314.3.0000.0068). All patients gave written informed consent before study entry.

\section{Competing interests}

The authors declare that they have no competing interests.

\section{Publisher's Note}

Springer Nature remains neutral with regard to jurisdictional claims in published maps and institutional affiliations. 
Received: 30 October 2017 Accepted: 12 April 2018

Published online: 27 April 2018

\section{References}

1. Preljevic VT, Osthus TB, Os I, Sandvik L, Opjordsmoen S, Nordhus $\mathbb{H}$, Dammen T. Anxiety and depressive disorders in dialysis patients: association to health-related quality of life and mortality. Gen Hosp Psychiatry. 2013; 35(6):619-24.

2. Balogun RA, Abdel-Rahman EM, Balogun SA, Lott EH, Lu JL, Malakauskas SM, Ma JZ, Kalantar-Zadeh K, Kovesdy CP. Association of depression and antidepressant use with mortality in a large cohort of patients with nondialysis-dependent CKD. Clin J Am Soc Nephrol : CJASN. 2012;7(11):1793-800.

3. Loosman WL, Rottier MA, Honig A, Siegert CE. Association of depressive and anxiety symptoms with adverse events in Dutch chronic kidney disease patients: a prospective cohort study. BMC Nephrol. 2015;16:155.

4. Tsai YC, Chiu YW, Hung CC, Hwang SJ, Tsai JC, Wang SL, Lin MY, Chen HC. Association of symptoms of depression with progression of CKD. Am J Kidney Dis. 2012;60(1):54-61.

5. Hedayati SS, Yalamanchili V, Finkelstein FO. A practical approach to the treatment of depression in patients with chronic kidney disease and endstage renal disease. Kidney Int. 2012;81(3):247-55.

6. Turkistani I, Nuqali A, Badawi M, Taibah O, Alserihy O, Morad M, Kalantan E. The prevalence of anxiety and depression among end-stage renal disease patients on hemodialysis in Saudi Arabia. Ren Fail. 2014;36(10):1510-5.

7. Johansen KL. Choice of dialysis modality in the United States. Arch Intern Med. 2011;171(2):107-9.

8. Covic A, Bammens B, Lobbedez T, Segall L, Heimburger O, van Biesen W, Fouque D, Vanholder R. Educating end-stage renal disease patients on dialysis modality selection: clinical advice from the European renal best practice (ERBP) advisory board. Nephrol Dial, Transplant. 2010;25(6):1757-9.

9. Levin A, Hemmelgarn B, Culleton B, Tobe S, McFarlane P, Ruzicka M, Burns K, Manns B, White C, Madore F, et al. Guidelines for the management of chronic kidney disease. CMAJ. 2008;179(11):1154-62.

10. Zigmond AS, Snaith RP. The hospital anxiety and depression scale. Acta Psychiatr Scand. 1983;67(6):361-70.

11. Cohen S, Kamarck T, Mermelstein R. A global measure of perceived stress. J Health Soc Behav. 1983;24(4):385-96.

12. Safdar N, Baakza H, Kumar H, Naqvi SA. Non-compliance to diet and fluid restrictions in haemodialysis patients. JPMA. J Pak Med Assoc. 1995;45(11):293-5.

13. Lee YJ, Kim MS, Cho S, Kim SR. Association of depression and anxiety with reduced quality of life in patients with predialysis chronic kidney disease. Int J Clin Pract. 2013;67(4):363-8.

14. Odden MC, Whooley MA, Shlipak MG. Depression, stress, and quality of life in persons with chronic kidney disease: the heart and soul study. Nephron Clin Pract. 2006;103(1):C1-7.

15. Ricardo AC, Fischer MJ, Peck A, Turyk M, Lash JP. Depressive symptoms and chronic kidney disease: results from the National Health and nutrition examination survey (NHANES) 2005-2006. Int Urol Nephrol. 2010;42(4):1063-8.

16. Andrade CP, Cruz MC, Urrutia M, Pereira O, Draibe SA, Nogueira-Martins LA, Sesso R. Evaluation of depressive symptoms in patients with chronic renal failure. J Nephrol. 2010;23(2):168-74

17. Abdel-Kader K, Myaskovsky L, Karpov I, Shah J, Hess R, Dew MA, Unruh M. Individual quality of life in chronic kidney disease: influence of age and dialysis modality. Clin J Am Soc Nephrol : CJASN. 2009;4(4):711-8.

18. Prior A, Fenger-Gron M, Larsen KK, Larsen FB, Robinson KM, Nielsen MG, Christensen KS, Mercer SW, Vestergaard M. The association between perceived stress and mortality among people with multimorbidity: a prospective population-based cohort study. Am J Epidemiol. 2016;184(3):199-210.

19. Maddock RJ, Moses JA Jr, Roth WT, King R, Murchison A, Berger PA. Serum phosphate and anxiety in major depression. Psychiatry Res. 1987;22(1):29-36.

20. Aalbers C, Emsley RA, Taljaard JJ. Serum phosphate and anxiety in major depression. Psychiatry Res. 1990;31(2):217.

21. Brautbar N, Leibovici $H$, Massry SG. On the mechanism of hypophosphatemia during acute hyperventilation: evidence for increased muscle glycolysis. Miner Electrolyte Metab. 1983;9(1):45-50.

Ready to submit your research? Choose BMC and benefit from:

- fast, convenient online submission

- thorough peer review by experienced researchers in your field

- rapid publication on acceptance

- support for research data, including large and complex data types

- gold Open Access which fosters wider collaboration and increased citations

- maximum visibility for your research: over $100 \mathrm{M}$ website views per year

At BMC, research is always in progress.

Learn more biomedcentral.com/submissions 